4

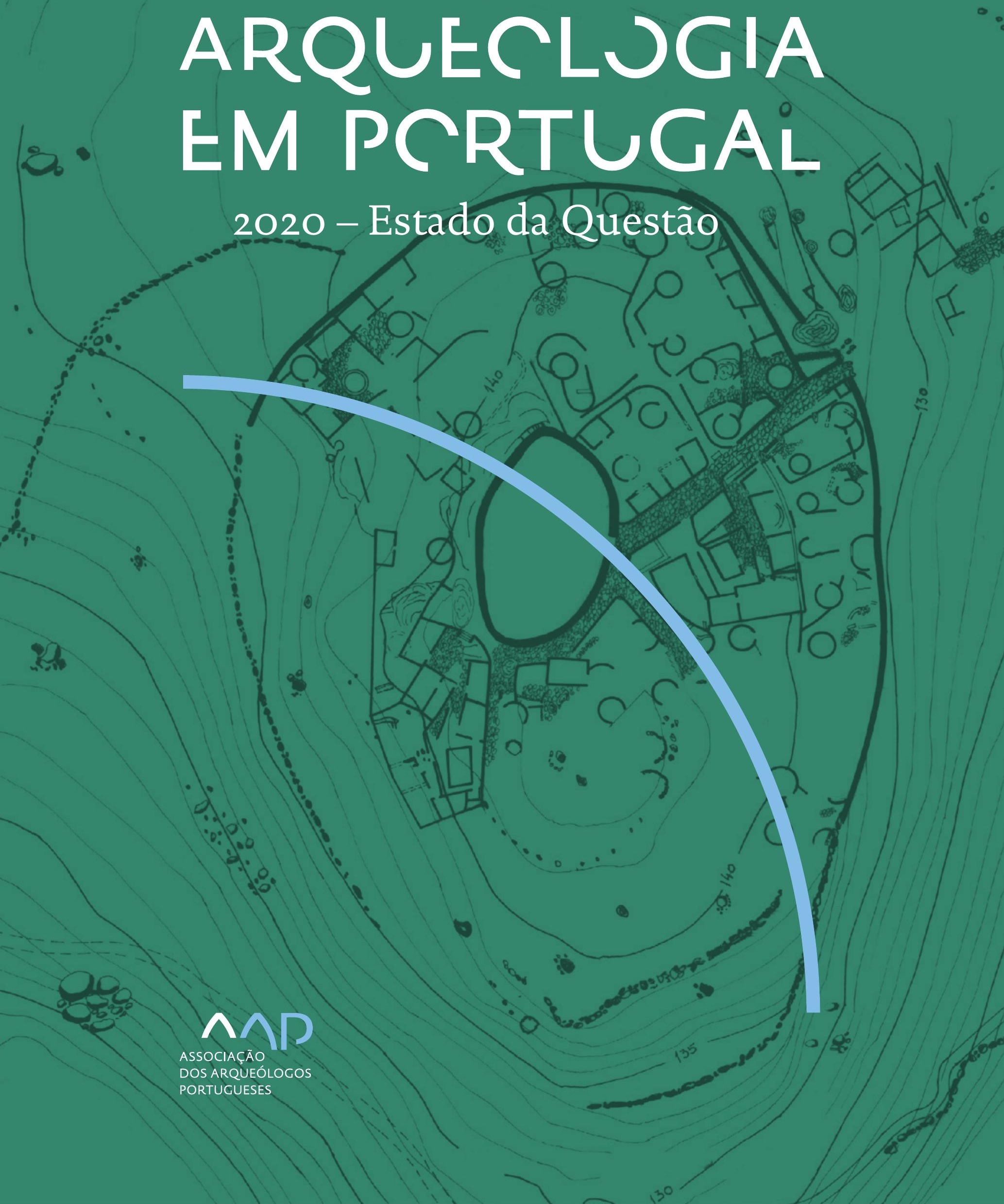


Coordenação editorial: José Morais Arnaud, César Neves e Andrea Martins Design gráfico: Flatland Design

AAP - ISBN: 978-972-9451-89-8

CITCEM - ISBN: 978-989-8970-25-1

Associação dos Arqueólogos Portugueses e CITCEM

Lisboa, 2020

O conteúdo dos artigos é da inteira responsabilidade dos autores. Sendo assim a Associação dos Arqueólogos Portugueses declina qualquer responsabilidade por eventuais equívocos ou questões de ordem ética e legal.

Desenho de capa:

Planta do castro de Monte Mozinho (Museu Municipal de Penafiel).

\section{$\hat{\wedge} \mathrm{P}$}

DOS ARQUEÓLOGOS PORTUGUESES

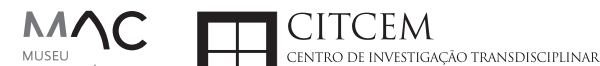
MUSEU
ARQUELLÓGICO
DO CARMO
U.PORTO

FLUP FACULDADE DE LETRAS
UNIVERSIDADE DO PORTO

Apoio

EC para a Ciência 


\section{Índice}

15 Prefácio

José Morais Arnaud

\section{Historiografia e Teoria}

17 Território, comunidade, memória e emoção: a contribuição da história da arqueologia (algumas primeiras e breves reflexões)

Ana Cristina Martins

25 Como descolonizar a arqueologia portuguesa?

Rui Gomes Coelho

41 Arqueologia e Modernidade: uma revisitação pessoal e breve de alguns aspetos da obra homónima de Julian Thomas de 2004

Vítor Oliveira Jorge

57 Dados para a História das Mulheres na Arqueologia portuguesa, dos finais do século XIX aos inícios do século XX: números, nomes e tabelas

Filipa Dimas / Mariana Diniz

73 Retractos da arqueologia portuguesa na imprensa: (in)visibilidades no feminino

Catarina Costeira / Elsa Luís

85 Arqueologia e Arqueólogos no Norte de Portugal Jacinta Bugalhão

101 Vieira Guimarães (1864-1939) e a arqueologia em Tomar: uma abordagem sobre o território e as gentes

João Amendoeira Peixoto / Ana Cristina Martins

115 Os memoráveis? A arqueologia algarvia na imprensa nacional e regional na presente centúria (2001-2019): características, visões do(s) passado(s) e a arqueologia

enquanto marca

Frederico Agosto / João Silva

129 A Evolução da Arqueologia Urbana e a Valorização Patrimonial no Barlavento Algarvio: Os casos de Portimão e Silves

Artur Mateus / Diogo Varandas / Rafael Boavida

\section{Gestão, Valorização e Salvaguarda do Património}

145 O Caderno Reivindicativo e as condições de trabalho em Arqueologia Miguel Rocha / Liliana Matias Carvalho / Regis Barbosa / Mauro Correia / Sara Simões / Jacinta Bugalhão / Sara Brito / Liliana Veríssimo Carvalho / Richard Peace / Pedro Peça / Cézer Santos

155 Os Estudos de Impacte Patrimonial como elemento para uma estratégia sustentável de minimização de impactes no âmbito de reconversões agrícolas Tiago do Pereiro

165 Salvaguarda de Património arqueológico em operações florestais: gestão e sensibilização Filipa Bragança / Gertrudes Zambujo / Sandra Lourenço / Belém Paiva / Carlos Banha / Frederico Tatá Regala / Helena Moura / Jacinta Bugalhão / João Marques / José Correia / Pedro Faria / Samuel Melro

179 Os valores do Património: uma investigação sobre os Sítios Pré-históricos de Arte Rupestre do Vale do Rio Côa e de Siega Verde José Paulo Francisco 
189 Conjugando recursos arqueológicos e naturais para potenciar as visitas ao Geoparque Litoral de Viana do Castelo (Noroeste de Portugal)

Hugo A. Sampaio / Ana M.S. Bettencourt / Susana Marinho / Ricardo Carvalhido

203 Áreas de Potencial Arqueológico na Região do Médio Tejo: Modelo Espacial Preditivo Rita Ferreira Anastácio / Ana Filipa Martins / Luiz Oosterbeek

223 Património Arqueológico e Gestão Territorial: O contributo da Arqueologia para a revisão do PDM de Avis

Ana Cristina Ribeiro

237 A coleção arqueológica do extinto Museu Municipal do Porto - Origens, Percursos e Estudos

Sónia Couto

251 Valpaços - uma nova carta arqueológica

Pedro Pereira / Maria de Fátima Casares Machado

263 Arqueologia na Cidade de Peniche

Adriano Constantino / Luís Rendeiro

273 Arqueologia Urbana: a cidade de Lagos como caso de Estudo Cátia Neto

285 Estratégias de promoção do património cultural subaquático nos Açores. O caso da ilha do Faial

José Luís Neto / José Bettencourt / Luís Borges / Pedro Parreira

297 Carta Arqueológica da Cidade Velha: Uma primeira abordagem

Jaylson Monteiro / Nireide Tavares / Sara da Veiga / Claudino Ramos / Edson Brito /

Carlos Carvalho / Francisco Moreira / Adalberto Tavares

311 Antropologia Virtual: novas metodologias para a análise morfológica e funcional Ricardo Miguel Godinho / Célia Gonçalves

\section{Didáctica da Arqueologia}

327 Como os projetos de Arqueologia podem contribuir para uma comunidade culturalmente mais consciente Alexandra Figueiredo / Claúdio Monteiro / Adolfo Silveira / Ricardo Lopes

337 Educação Patrimonial - Um cidadão esclarecido é um cidadão ativo! Ana Paula Almeida

351 A aproximação da Arqueologia à sala de aula: um caso de estudo no $3^{\circ}$ ciclo do Ensino Básico Luís Serrão Gil

363 Arqueologia 3.o - Pensar e comunicar a Arqueologia para um futuro sustentável Mónica Rolo

377 “Conversa de Arqueólogos" - Divulgar a Arqueologia em tempos de Pandemia Diogo Teixeira Dias

389 Escola Profissional de Arqueologia: desafios e oportunidades Susana Nunes / Dulcineia Pinto / Júlia Silva / Ana Mascarenhas

399 Os Museus de Arqueologia e os Jovens: a oferta educativa para o público adolescente Beatriz Correia Barata / Leonor Medeiros

411 O museu universitário como mediador entre a ciência e a sociedade: o exemplo da secção de arqueologia no Museu de História Natural e da Ciência da Universidade do Porto (MHNC-UP)

Rita Gaspar 
421 Museu de Lanifícios: Real Fábrica de Panos. Atividades no âmbito da Arqueologia Beatriz Correia Barata / Rita Salvado

427 Arqueologia Pública e o caso da localidade da Mata (Torres Novas) Cláudia Manso / Ana Rita Ferreira / Cristiana Ferreira / Vanessa Cardoso Antunes

431 Do sítio arqueológico ao museu: um percurso (também) didático Lídia Fernandes

447 Estão todos convidados para a Festa! E para dançar também... O projecto do Serviço Educativo do Museu Arqueológico do Carmo na $5^{\underline{a}}$ Edição da Festa da Arqueologia Rita Pires dos Santos

459 O “Clã de Carenque”, um projeto didático de arqueologia Eduardo Gonzalez Rocha

469 Mediação cultural: peixe que puxa carroça nas Ruínas Romanas de Troia Inês Vaz Pinto / Ana Patrícia Magalhães / Patrícia Brum / Filipa Santos

481 Didática Arqueológica, experiências do Projeto Mértola Vila Museu Maria de Fátima Palma / Clara Rodrigues / Susana Gómez / Lígia Rafael

\section{Arte Rupestre}

497 Os inventários de arte rupestre em Portugal Mila Simões de Abreu

513 O projeto FIRST-ART - conservação, documentação e gestão das primeiras manifestações de arte rupestre no Sudoeste da Península Ibérica: as grutas do Escoural e Maltravieso Sara Garcês / Hipólito Collado / José Julio García Arranz / Luiz Oosterbeek / António Carlos Silva / Pierluigi Rosina / Hugo Gomes / Anabela Borralheiro Pereira / George Nash / Esmeralda Gomes / Nelson Almeida / Carlos Carpetudo

523 Trabalhos de documentação de arte paleolítica realizados no âmbito do projeto PalæoCôa André Tomás Santos / António Fernando Barbosa / Luís Luís / Marcelo Silvestre / Thierry Aubry

537 Imagens fantasmagóricas, silhuetas elusivas: as figuras humanas na arte do Paleolítico Superior da região do Côa Mário Reis

$55^{1}$ Os motivos zoomórficos representados nas placas de tear de Vila Nova de São Pedro (Azambuja, Portugal) Andrea Martins / César Neves / José M. Arnaud / Mariana Diniz

571 Arte Rupestre do Monte de Góios (Lanhelas, Caminha). Síntese dos resultados dos trabalhos efectuados em 2007-2009 Mário Varela Gomes

599 Gravuras rupestres de barquiformes no Monte de S. Romão, Guimarães, Noroeste de Portugal Daniela Cardoso

613 Círculos segmentados gravados na Bacia do Rio Lima (Noroeste de Portugal): contributos para o seu estudo Diogo Marinho / Ana M.S. Bettencourt / Hugo Aluai Sampaio

631 Equídeos gravados no curso inferior do Rio Mouro, Monção (NW Portugal). Análise preliminar Coutinho, L.M. / Bettencourt, A.M.S / Sampaio, Hugo A.S

645 Paletas na Arte Rupestre do Noroeste de Portugal. Inventário preliminar Bruna Sousa Afonso / Ana M. S. Bettencourt / Hugo A. Sampaio 


\section{Pré-História}

661 O projeto Miño/Minho: balanço de quatro anos de trabalhos arqueológicos Sérgio Monteiro-Rodrigues / João Pedro Cunha-Ribeiro / Eduardo Méndez-Quintas / Carlos Ferreira / Pedro Xavier / José Meireles / Alberto Gomes / Manuel Santonja / Alfredo Pérez-González

677 A ocupação paleolítica da margem esquerda do Baixo Minho: a indústria lítica do sítio de Pedreiras 2 (Monção, Portugal) e a sua integração no contexto regional Carlos Ferreira / João Pedro Cunha-Ribeiro / Sérgio Monteiro-Rodrigues / Eduardo Méndez-Quintas / Pedro Xavier / José Meireles / Alberto Gomes / Manuel Santonja / Alfredo Pérez-González

693 O sítio acheulense do Plistocénico médio da Gruta da Aroeira Joan Daura / Montserrat Sanz / Filipa Rodrigues / Pedro Souto / João Zilhão

703 As sociedades neandertais no Barlavento algarvio: modelos preditivos com recurso aos SIG

Daniela Maio

715 A utilização de quartzo durante o Paleolítico Superior no território dos vales dos rios Vouga e Côa

Cristina Gameiro / Thierry Aubry / Bárbara Costa / Sérgio Gomes / Luís Luís / Carmen Manzano / André Tomás Santos

733 Uma perspetiva diacrónica da ocupação do concheiro do Cabeço da Amoreira (Muge, Portugal) a partir da tecnologia lítica Joana Belmiro / João Cascalheira / Célia Gonçalves

745 Novos dados sobre a Pré-história Antiga no concelho de Palmela. A intervenção arqueológica no sítio do Poceirão I

Michelle Teixeira Santos

757 Problemas em torno de Datas Absolutas Pré-Históricas no Norte do Alentejo Jorge de Oliveira

771 Povoamento pré-histórico nas áreas montanhosas do NO de Portugal: o Abrigo 1 de Vale de Cerdeira Pedro Xavier / José Meireles / Carlos Alves

783 Apreciação do povoamento do Neolítico Inicial na Baixa Bacia do Douro. A Lavra I (Serra da Aboboreira) como caso de estudo Maria de Jesus Sanches

797 O Processo de Neolitização na Plataforma do Mondego: os dados do Sector C do Outeiro dos Castelos de Beijós (Carregal do Sal)

João Carlos de Senna-Martinez / José Manuel Quintã Ventura / Andreia Carvalho / Cíntia Maurício

823 Novos trabalhos na Lapa da Bugalheira (Almonda, Torres Novas) Filipa Rodrigues / Pedro Souto / Artur Ferreira / Alexandre Varanda / Luís Gomes / Helena Gomes / João Zilhão

837 A pedra polida e afeiçoada do sítio do Neolítico médio da Moita do Ourives (Benavente, Portugal)

César Neves

857 Casal do Outeiro (Encarnação, Mafra): novos contributos para o conhecimento do povoamento do Neolítico final na Península de Lisboa.

Cátia Delicado / Carlos Maneira e Costa / Marta Miranda / Ana Catarina Sousa

873 Stresse infantil, morbilidade e mortalidade no sítio arqueológico do Neolítico Final/ Calcolítico ( $4^{\circ}$ e $3^{\circ}$ milénio a.C.) do Monte do Carrascal 2 (Ferreira do Alentejo, Beja) Liliana Matias de Carvalho / Sofia N. Wasterlain 
885 Come together: O Conjunto Megalítico das Motas (Monção, Viana do Castelo) e as expressões Campaniformes do Alto Minho Ana Catarina Basílio / Rui Ramos

899 Trabalhos arqueológicos no sítio Calcolítico da Pedreira do Poio Carla Magalhães / João Muralha / Mário Reis / António Batarda Fernandes

913 O sítio arqueológico de Castanheiro do Vento. Da arquitectura do sítio à arquitectura de um território João Muralha Cardoso

925 Estudo zooarqueológico das faunas do Calcolítico final de Vila Nova de São Pedro (Azambuja, Portugal): Campanhas de 2017 e 2018 Cleia Detry / Ana Catarina Francisco / Mariana Diniz / Andrea Martins / César Neves / José Morais Arnaud

943 As faunas depositadas no Museu Arqueológico do Carmo provenientes de Vila Nova de São Pedro (Azambuja): as campanhas de 1937 a 1967 Ana Catarina Francisco / Cleia Detry / César Neves / Andrea Martins / Mariana Diniz / José Morais Arnaud

959 Análise funcional de material lítico em sílex do castro de Vila Nova de S. Pedro (Azambuja, Portugal): uma primeira abordagem Rafael Lima

971 O recinto da Folha do Ouro 1 (Serpa) no contexto dos recintos de fossos calcolíticos alentejanos

António Carlos Valera / Tiago do Pereiro / Pedro Valério / António M. Monge Soares

\section{Proto-História}

987 Produção de sal marinho na Idade do Bronze do noroeste Português. Alguns dados para uma reflexão

Ana M. S. Bettencourt / Sara Luz / Nuno Oliveira / Pedro P. Simões / Maria Isabel C. Alves / Emílio Abad-Vidal

1001 A estátua-menir do Pedrão ou de São Bartolomeu do Mar (Esposende, noroeste de Portugal) no contexto arqueológico da fachada costeira de entre os rios Neiva e Cávado Ana M. S. Bettencourt / Manuel Santos-Estévez / Pedro Pimenta Simões / Luís Gonçalves

1015 O Castro do Muro (Vandoma/Baltar, Paredes) - notas para uma biografia de ocupação da Idade do Bronze à Idade Média

Maria Antónia D. Silva / Ana M. S. Bettencourt / António Manuel S. P. Silva / Natália Félix

1031 Do Bronze Final à Idade Média - continuidades e hiatos na ocupação de Povoados em Oliveira de Azeméis João Tiago Tavares / Adriaan de Man

1041 As faunas do final da Idade do Bronze no Sul de Portugal: leituras desde o Outeiro do Circo (Beja)

Nelson J. Almeida / Íris Dias / Cleia Detry / Eduardo Porfírio / Miguel Serra

1055 A Espada do Monte das Oliveiras (Serpa) - uma arma do Bronze Pleno do Sudoeste Rui M. G. Monge Soares / Pedro Valério / Mariana Nabais / António M. Monge Soares

1065 São Julião da Branca (Albergaria-a-Velha) - Investigação e valorização de um povoado do Bronze Final

António Manuel S. P. Silva / Paulo A. P. Lemos / Sara Almeida e Silva / Edite Martins de Sá

1083 Do castro de S. João ao Mosteiro de Santa Clara: notícia de uma intervenção arqueológica, em Vila do Conde Rui Pinheiro 
1095 O castro de Ovil (Espinho), um quarto de século de investigação - resultados e questões em aberto

Jorge Fernando Salvador / António Manuel S. P. Silva

1111 O Castro de Salreu (Estarreja), um povoado proto-histórico no litoral do Entre Douro e Vouga

Sara Almeida e Silva / António Manuel S. P. Silva / Paulo A. P. Lemos / Edite Martins de Sá

1127 Castro de Nossa Senhora das Necessidades (Sernancelhe): uma primeira análise artefactual Telma Susana O. Ribeiro

${ }_{1141}$ A cividade de Bagunte. O estado atual da investigação Pedro Brochado de Almeida

1153 Zoomorfos na cerâmica da Idade do Ferro no NW Peninsular: inventário, cronologias e significado Nuno Oliveira / Cristina Seoane

1163 Vasos gregos em Portugal: diferentes maneiras de contar a história do intercâmbio cultural na Idade do Ferro

Daniela Ferreira

1175 Os exotica da necrópole da Idade do Ferro do Olival do Senhor dos Mártires (Alcácer do Sal) no seu contexto regional

Francisco B. Gomes

\section{Antiguidade Clássica e Tardia}

1191 O uso de madeira como combustível no sítio da Quinta de Crestelos (Baixo Sabor): da Idade do Ferro à Romanização Filipe Vaz / João Tereso / Sérgio Simões Pereira / José Sastre / Javier Larrazabal Galarza / Susana Cosme / José António Pereira / Israel Espi

1207 Cultivos de Época Romana no Baixo Sabor: continuidade em tempos de mudança? João Pedro Tereso / Sérgio Simões Pereira / Filipe Santos / Luís Seabra / Filipe Vaz

1221 A casa romana na Hispânia: aplicação dos modelos itálicos nas províncias ibéricas Fernanda Magalhães / Diego Machado / Manuela Martins

1235 As pinturas murais romanas da Rua General Sousa Machado, n. ${ }^{5}$ 1, Chaves José Carvalho

1243 Trás do Castelo (Vale de Mir, Pegarinhos, Alijó) - Uma exploração agrícola romana do Douro

Tony Silvino / Pedro Pereira

1255 A sequência de ocupação no quadrante sudeste de Bracara Augusta: as transformações de uma unidade doméstica Lara Fernandes / Manuela Martins

1263 Os Mosaicos com decoração geométrica e geométrico-vegetalista dos sítios arqueológicos da área do Conuentus Bracaraugustanus. Novas abordagens quanto à conservação, restauro, decoração e datação Maria de Fátima Abraços / Licínia Wrench

1277 “Casa Romana” do Castro de São Domingos (Cristelos, Lousada): Escavação, Estudo e Musealização Paulo André de P. Lemos

1291 A arqueobotânica no Castro de Guifões (Matosinhos, Noroeste de Portugal): O primeiro estudo carpológico

Luís Seabra / Andreia Arezes / Catarina Magalhães / José Varela / João Pedro Tereso 
1305 Um Horreum Augustano na Foz do Douro (Monte do Castelo de Gaia, Vila Nova de Gaia) Rui Ramos

1311 Ponderais romanos na Lusitânia: padrões, formas, materiais e contextos de utilização Diego Barrios Rodríguez

1323 Um almofariz centro-itálico na foz do Mondego

Marco Penajoia

1335 Estruturas romanas de Carnide - Lisboa Luísa Batalha / Mário Monteiro / Guilherme Cardoso

1347 O contexto funerário do sector da "necrópole NO" da Rua das Portas de S. Antão (Lisboa): o espaço, os artefactos, os indivíduos e a sua interconectividade na interpretação do passado Sílvia Loja, José Carlos Quaresma, Nelson Cabaço, Marina Lourenço, Sílvia Casimiro, Rodrigo Banha da Silva, Francisca Alves-Cardoso

${ }_{1361}$ Povoamento em época Romana na Amadora - resultados de um projeto pluridisciplinar Gisela Encarnação / Vanessa Dias

1371 A Arquitectura Residencial em Mirobriga (Santiago do Cacém): contributo a partir de um estudo de caso Filipe Sousa / Catarina Felício

${ }_{1385}$ O fim do ciclo. Saneamento e gestão de resíduos nos edifícios termais de Mirobriga (Santiago do Cacém)

Catarina Felício / Filipe Sousa

1399 Balsa, Topografia e Urbanismo de uma Cidade Portuária Vítor Silva Dias / João Pedro Bernardes / Celso Candeias / Cristina Tété Garcia

1413 No Largo das Mouras Velhas em Faro (2017): novas evidências da necrópole norte de Ossonoba e da sua ocupação medieval Ricardo Costeira da Silva / Paulo Botelho / Fernando Santos / Liliana Nunes

1429 Instrumentos de pesca recuperados numa fábrica de salga em Ossonoba (Faro) Inês Rasteiro / Ricardo Costeira da Silva / Paulo Botelho

1439 A Necrópole Romana do Eirô, Duas Igrejas (Penafiel): intervenção arqueológica de 2016 Laura Sousa / Teresa Soeiro

1457 Ritual, descarte ou afetividade? A presença de Canis lupus familiaris na Necrópole Noroeste de Olisipo (Lisboa)

Beatriz Calapez Santos / Sofia Simões Pereira / Rodrigo Banha da Silva / Sílvia Casimiro / Cleia Detry / Francisca Alves Cardoso

1467 Dinâmicas económicas em Bracara na Antiguidade Tardia Diego Machado / Manuela Martins / Fernanda Magalhães / Natália Botica

1479 Cerâmicas e Vidros da Antiguidade Tardia do Edifício sob a Igreja do Bom Jesus (Vila Nova de Gaia) Joaquim Filipe Ramos

1493 Novos contributos para a topografia histórica de Mértola no período romano e na Antiguidade Tardia Virgílio Lopes

\section{8. Época Medieval}

1511 Cerâmicas islâmicas no Garb setentrional "português": algumas evidências e incógnitas Constança dos Santos / Helena Catarino / Susana Gómez / Maria José Gonçalves / Isabel Inácio / Gonçalo Lopes / Jacinta Bugalhão / Sandra Cavaco / Jaquelina Covaneiro / Isabel Cristina Fernandes / Ana Sofia Gomes 
1525 Contributo para o conhecimento da cosmética islâmica, em Silves, durante a Idade Média Rosa Varela Gomes

1537 Yábura e o seu território - uma análise histórico-arqueológica de Évora entre os séculos VIII-XII José Rui Santos

1547 A encosta sul do Castelo de Palmela - resultados preliminares da escavação arqueológica Luís Filipe Pereira / Michelle Teixeira Santos

1559 A igreja de São Lourenço (Mouraria, Lisboa): um conjunto de silos e de cerâmica medieval islâmica

Andreia Filipa Moreira Rodrigues

1571 O registo material de movimentações populacionais no Médio Tejo, durante os séculos XII-XIII. Dois casos de "sunken featured buildings", nos concelhos de Cartaxo e Torres Novas Marco Liberato / Helena Santos / Nuno Santos

1585 O nordeste transmontano nos alvores da Idade média. Notas para reflexão Ana Maria da Costa Oliveira

1601 Sepulturas escavadas na rocha do Norte de Portugal e do Vale do Douro: primeiros resultados do Projecto SER-NPVD

Mário Jorge Barroca / César Guedes / Andreia Arezes / Ana Maria Oliveira

1619 "Portucalem Castrum Novum" entre o Mediterrâneo e o Atlântico: o estudo dos materiais cerâmicos alto-medievais do arqueossítio da rua de D. Hugo, nํ. 5 (Porto) João Luís Veloso

1627 A Alta Idade Média na fronteira de Lafões: notas preliminares sobre a Arqueologia no Concelho de Vouzela

Manuel Luís Real / Catarina Tente

1641 Um conjunto cerâmico medieval fora de portas: um breve testemunho aveirense Susana Temudo

${ }_{1651}$ Os Lóios do Porto: uma perspetiva integrada no panorama funerário da Baixa Idade Média à Época Moderna em meios urbanos em Portugal

Ana Lema Seabra

1659 O Caminho Português Interior de Santiago como eixo viário na Idade Média Pedro Azevedo

1665 Morfologia Urbana: Um exercício em torno do Castelo de Ourém André Donas-Botto / Jaqueline Pereira

1677 Intervenção arqueológica na Rua Marquês de Pombal/Largo do Espírito Santo (Bucelas, Loures)

Florbela Estêvão / Nathalie Antunes-Ferreira / Dário Ramos Neves / Inês Lisboa

1691 O Cemitério Medieval do Poço do Borratém e a espacialidade funerária na cidade de Lisboa Inês Belém / Vanessa Filipe / Vasco Noronha Vieira / Sónia Ferro / Rodrigo Banha da Silva

1705 Um Espaço Funerário Conventual do séc. XV em Lisboa: o caso do Convento de São Domingos da Cidade Sérgio Pedroso / Sílvia Casimiro / Rodrigo Banha da Silva / Francisca Alves Cardoso

\section{9. Época Moderna e Contemporânea}

1721 Arqueologia Moderna em Portugal: algumas reflexões críticas em torno da quantificação de conjuntos cerâmicos e suas inferências históricas e antropológicas Rodrigo Banha da Silva / André Bargão / Sara da Cruz Ferreira

1733 Faianças de dois contextos entre os finais do século XVI e XVIII do Palácio dos Condes de Penafiel, Lisboa

Martim Lopes / Tomás Mesquita 
1747 Um perfil de consumo do século XVIII na foz do Tejo: O caso do Mercado da Ribeira, Lisboa Sara da Cruz Ferreira / Rodrigo Banha da Silva / André Bargão

1761 Os Cachimbos dos Séculos XVII e XVIII do Palácio Mesquitela e Convento dos Inglesinhos (Lisboa)

Inês Simão / Marina Pinto / João Pimenta / Sara da Cruz Ferreira / André Bargão / Rodrigo Banha da Silva

1775 "Tomar os fumos da erua que chamão em Portugal erua sancta». Estudo de Cachimbos provenientes da Rua do Terreiro do Trigo, Lisboa

Miguel Martins de Sousa / José Pedro Henriques / Vanessa Galiza Filipe

1787 Cachimbos de Barro Caulínitico da Sé da Cidade Velha (República de Cabo Verde)

Rodrigo Banha da Silva / João Pimenta / Clementino Amaro

1801 Algumas considerações sobre espólio não cerâmico recuperado no Largo de Jesus (Lisboa) Carlos Boavida

1815 Adereços de vidro, dos séculos XVI-XVIII, procedentes do antigo Convento de Santana de Lisboa (anéis, braceletes e contas)

Joana Gonçalves / Rosa Varela Gomes / Mário Varela Gomes

1837 Da ostentação, luxo e poder à simplicidade do uso quotidiano: arqueologia e simbologia de joias e adornos da Idade Moderna Portuguesa Jéssica Iglésias

1849 Os amuletos em Portugal - dos objetos às superstições: o coral vermelho Alexandra Vieira

1865 Cerâmicas de Vila Franca de Xira nos séculos XV e XVI Eva Pires

1879 «Não passa por teu o que me pertence». Marcas de individualização associadas a faianças do Convento de Nossa Senhora de Aracoeli, Alcácer do Sal Catarina Parreira / Íris Fragoso / Miguel Martins de Sousa

1891 Cerâmica de Leiria: alguns focos de produção

Jaqueline Pereira / André Donas-Botto

1901 Os Fornos na Rua da Biquinha, em Óbidos Hugo Silva / Filipe Oliveira

1909 A casa de Pêro Fernandes, contador dos contos de D. Manuel I: o sítio arqueológico da Silha do Alferes, Seixal (século XVI) Mariana Nunes Ferreira

1921 O Alto da Vigia (Sintra) e a vigilância e defesa da costa Alexandre Gonçalves / Sandra Santos

1937 O contexto da torre sineira da Igreja de Santa Maria de Loures Paulo Calaveira / Martim Lopes

1949 A Necrópole do Hospital Militar do Castelo de São Jorge e as práticas funerárias na Lisboa de Época Moderna Susana Henriques / Liliana Matias de Carvalho / Ana Amarante / Sofia N. Wasterlain

1963 SAND - Sarilhos Grandes Entre dois Mundos: o adro da Igreja e a Paleobiologia dos ossos humanos recuperados

Paula Alves Pereira / Roger Lee Jesus / Bruno M. Magalhães

1975 Expansão urbana da vila de Cascais no século XVII e XVIII: a intervenção arqueológica na Rua da Vitória no 15 a 17

Tiago Pereira / Vanessa Filipe

1987 Novos dados para o conhecimento do Urbanismo de Faro em época Moderna Ana Rosa 
1995 Um exemplo de Arqueologia Urbana em Alcoutim: o Antigo Edifício dos CTT Marco Fernandes / Marta Dias / Alexandra Gradim / Virgílio Lopes / Susana Gómez Martínez

2007 Palácio dos Ferrazes (Rua das Flores/Rua da Vitória, Porto): a cocheira de Domingos Oliveira Maia

Francisco Raimundo

2021 As muitas vidas de um edifício urbano: História, Arqueologia e Antropologia no antigo Recreatório Paroquial de Penafiel Helena Bernardo / Jorge Sampaio / Marta Borges

2035 O convento de Nossa Senhora da Esperança de Ponta Delgada: o contributo da arqueologia para o conhecimento de um monumento identitário João Gonçalves Araújo / N’Zinga Oliveira

2047 Arqueologia na ilha do Corvo... em busca da capela de Nossa Senhora do Rosário Tânia Manuel Casimiro / José Luís Neto / Luís Borges / Pedro Parreira

2059 Perdidos à vista da Costa. Trabalhos arqueológicos subaquáticos na Barra do Tejo Jorge Freire / José Bettencourt / Augusto Salgado

2071 Arqueologia marítima em Cabo Verde: enquadramento e primeiros resultados do projecto CONCHA

José Bettencourt / Adilson Dias / Carlos Lima / Christelle Chouzenoux / Cristóvão Fonseca / Dúnia Pereira / Gonçalo Lopes / Inês Coelho / Jaylson Monteiro / José Lima / Maria Eugénia Alves / Patrícia Carvalho / Tiago Silva

2085 Trabalhos arqueológicos na Cidade Velha (Ribeira Grande de Santiago, Cabo Verde): reflexões sobre um projecto de investigação e divulgação patrimonial André Teixeira / Jaylson Monteiro / Mariana Mateus / Nireide Tavares / Cristovão Fonseca / Gonçalo C. Lopes / Joana Bento Torres / Dúnia Pereira / André Bargão / Aurélie Mayer / Bruno Zélie / Carlos Lima / Christelle Chouzenoux / Inês Henriques / Inês Pinto Coelho / José Lima / Patrícia Carvalho / Tiago Silva

2103 A antiga fortificação de Quelba / Khor Kalba (E.A.U.). Resultados de quatro campanhas de escavações, problemáticas e perspectivas futuras Rui Carita / Rosa Varela Gomes / Mário Varela Gomes / Kamyar Kamyad

2123 Colónias para homens novos: arqueologia da colonização agrária fascista no noroeste ibérico Xurxo Ayán Vila / José Mạ . Señorán Martín 


\title{
UMA PERSPETIVA DIACRÓNICA DA OCUPAÇÃO DO CONCHEIRO DO CABEÇO DA AMOREIRA (MUGE, PORTUGAL) A PARTIR DA TECNOLOGIA LÍTICA
}

\author{
Joana Belmiro' $^{1}$, João Cascalheira², Célia Gonçalves ${ }^{3}$
}

\begin{abstract}
RESUMO
O presente estudo apresenta os resultados preliminares obtidos da análise tecnológica aos materiais líticos do concheiro mesolítico do Cabeço da Amoreira (Muge, Portugal) provenientes da última década de trabalhos arqueológicos. O principal objetivo passa por explorar a variabilidade tecnológica e matérias-primas nas duas principais áreas de escavação do sítio arqueológico, de forma a caracterizar os vários momentos de ocupação. Foi aplicada uma abordagem de análise tipológica e de atributos a todos os materiais líticos. Os resultados sugerem uma diferenciação clara dos conjuntos líticos no que diz respeito à tecnologia e tipologia, sendo detetados padrões de associação destas variáveis com as diferentes composições sedimentares das camadas identificadas. As diferenças são, sobretudo, ao nível da frequência das matérias-primas, núcleos e utensílios retocados. Palavras-chave: Mesolítico, Muge, Cabeço da Amoreira, Análise lítica.
\end{abstract}

\begin{abstract}
This study presents preliminary results from a technological analysis of lithic artefacts from the Mesolithic shellmidden of Cabeço da Amoreira (Muge, Portugal). The main goal was to understand the technological and raw material variability within the two main excavation areas of the site, in order to characterize the different occupation moments. A typological and attribute approach was used in the analysis. The results suggest a clear distinction of the lithic assemblages, associated with the sedimentary differences identified in the composition of the several layers. This separation can be found mostly in the frequencies of raw materials, cores and retouched tools.
\end{abstract}

Keywords: Mesolithic, Muge, Cabeço da Amoreira, Lithic analysis.

\section{INTRODUÇÃO}

O concheiro mesolítico do Cabeço da Amoreira localiza-se no centro de Portugal, na margem esquerda da ribeira de Muge (Figuras IA e 1B). O sítio localiza-se no topo de um terraço fluvial a cerca de 20 metros acima do atual nível do mar e apresenta uma forma elíptica com c. de $90 \mathrm{~m}$ de comprimento (N-S) e 50 m de largura (E-O) (Roche, 1964/1965). Durante a ocupação do concheiro, este estaria localizado perto de um ecossistema de água salobra com recursos marinhos abundantes (van der Schriek \& alii, 2007, 2008). A utilização destes recursos pelas populações mesolíticas é evidente nas variadas ocupações e concheiros presentes ao longo dos terraços da ribeira de Muge e outros tributários do rio Tejo (Bicho \& alii, 2013). O Cabeço da Amoreira destaca-se pela sua extensão horizontal e estratigráfica, e pelas suas camadas ricas em materiais arqueológicos e uma alta frequência de enterramentos humanos (Bicho \& alii, 2011, 2013; Detry \& Cardoso, 2010; Cunha, Cardoso \& Umbelino, 2003).

O concheiro do Cabeço da Amoreira foi identificado em 1864 por Carlos Ribeiro (1884), sendo que des-

\footnotetext{
1. ICArEHB, Universidade do Algarve; jnetobelmiro@gmail.com

2. ICArEHB, Universidade do Algarve; jmcascalheira@ualg.pt

3. ICArEHB, Universidade do Algarve; cmgoncalves@ualg.pt
} 
de então, o sítio tem contado com várias escavações arqueológicas: durante o século $\mathrm{XX}$, na década de 30, por Mendes Corrêa (1933) e, na década de 6o, por Jean Roche e Veiga Ferreira (Roche, 1966). Entre 1997 e 2001 José Rolão retoma os trabalhos com o objetivo de realizar um estudo geomorfológico e paleoambiental da região, em particular entre as ribeiras Fonte da Moça e Magos (Rolão, 1999; Rolão, Joaquinito \& Gonzaga, 2006). Mais recentemente, em 2008, novos trabalhos foram iniciados no sítio arqueológico do Cabeço da Amoreira no âmbito de um projeto interdisciplinar liderado por Nuno Bicho e financiado pela Fundação para a Ciência e Tecnologia (FCT), com o objetivo de estudar o desenvolvimento regional tecnológico, económico e social dos últimos caçadores-recolectores do vale do Tejo, (Bicho \& alii, 2011).

Desde então os trabalhos arqueológicos têm continuado graças aos sucessivos projetos alvo de financiamento por instituições nacionais e internacionais, encontrando-se atualmente em curso um novo projeto sob a direção de Célia Gonçalves. Os trabalhos a partir de 2008 contaram não só com abordagens interdisciplinares, assim como com a adoção de metodologias tecnológicas inovadoras e recentes, como a utilização de estações totais, que permitem a recolha de informação espacial detalhada. A escavação é realizada através da decapagem de níveis de $5 \mathrm{~cm}$, seguindo as camadas naturais e antrópicas identificadas. Todos os materiais com dimensões superiores a $2 \mathrm{~cm}$, ou com dimensões inferiores mas inteiros (e.g., microfauna, lamelas inteiras ou pinças de caranguejo) são cotados com recurso a uma estação total aos quais são atribuídos um código de barras e informações contextuais como o tipo de artefacto e informação tridimensional. Todo o sedimento escavado é colocado num balde de 10 litros, ao qual são atribuídas coordenadas de um ponto central da área escavada, sendo todo sedimento crivado a seco com malhas $1 \mathrm{~mm}$ e $3 \mathrm{~mm}$, de forma a recolher materiais de pequenas dimensões (Bicho \& alii, 2011).

Os recentes trabalhos no Cabeço da Amoreira focaram-se, maioritariamente, em duas áreas: $\mathrm{S} 1$, a noroeste (quadrados $\mathrm{G}$ a L) e S2, a este (quadrados A e B) (Figura ${ }_{1} \mathrm{C}$ ), ainda que nas campanhas anteriores a 2012 tenha sido escavada uma área mais extensa (camada 1, 1b e 2). A metodologia de escavação empregue permitiu até ao momento a identificação de várias camadas (Tabela 1 ), com significativa varia- ção lateral (Figuras 2 e 3) e diferenças marcadas entre as duas áreas. Ao longo das diferentes camadas destaca-se a presença abundante de fragmentos de conchas, restos faunísticos, líticos, adornos, seixos e termoclastos.

Bicho \& alii (2011) sugere que o sítio apresentou uma função residencial inicialmente, provavelmente simultânea, mas espacialmente separada, de uma função funerária. Depois desse momento, há poucas evidências de ocupações de tipo residencial, sendo que o sítio provavelmente representava um local para exploração de recursos, principalmente conquíferos. Baseado nas datações obtidas através de várias amostras, os cerca de $3 \mathrm{~m}$ de depósitos ricos em fragmentos de conchas parecem ter-se depositado num período relativamente rápido, possivelmente em várias fases curtas, entre ca. 7900 e 7500 cal. BP (Bicho \& alii, 2013). A identificação de fragmentos de cerâmica e enterramentos humanos no topo do concheiro, bem como os vestígios de áreas escavadas em torno do concheiro, revelaram ainda uma importante ocupação neolítica do sítio (Bicho \& alii, 2013; Umbelino 2006).

Além do entendimento do sítio arqueológico como um espaço não residencial durante a maior parte da ocupação, estão ainda por entender as possíveis variações funcionais dentro das várias camadas, que possam permitir a identificação de momentos ou comportamentos específicos sincrónicos e diacrónicos. Através da análise micromorfológica dos sedimentos, Aldeias e Bicho (2015) salientam padrões de ocupação complexos, incluindo ações de redeposição e arrastamento de sedimentos e materiais.

Sendo que estudos recentes demonstram a existência de uma complexidade nas várias ocupações e camadas, encontra-se estabelecida a oportunidade de testar variações ocupacionais possivelmente refletidas na cultura material, em especial na indústria lítica. Paralelamente, recorrendo aos dados espaciais obtidos durante as escavações é possível correlacionar a tecnologia lítica com outros dados como a frequência de restos faunísticos ou presença de carvões, de forma a melhor entender as características das ocupações.

\section{MATERIAIS E MÉTODOS}

Para cumprir os objetivos deste estudo, foram analisados os materiais líticos recolhidos nas campanhas de escavação do concheiro do Cabeço da Amoreira 
após 2008. Foram utilizados materiais de todas as camadas arqueológicas e estruturas individualizadas durante a escavação (com exceção da camada 1 e $\mathrm{ib}$, por serem camadas significativamente afetadas por processos pós-deposicionais naturais e antrópicos; Cascalheira \& Gonçalves, 2012). De forma a reduzir a dimensão da amostra, foram analisados apenas os materiais com dimensões superiores a 2 $\mathrm{cm}$ (cotados tridimensionalmente com recurso a estação total) das duas áreas de escavação principais dentro do concheiro do Cabeço da Amoreira.

Tendo em conta a existência de uma grande variabilidade na quantidade de materiais ao longo das várias camadas, foram apenas consideradas as camadas com mais de 10 artefactos (excluindo fragmentos de debitagem). Foram também colapsadas as camadas individualizadas durante a escavação por apresentarem maiores concentrações de conchas de uma determinada espécie (e.g., PITra, PITib ou PITıc) ainda que as características sedimentares fossem iguais à camada envolvente.

Foi aplicada uma abordagem de análise de atributos tecnológicos e tipológicos, utilizando literatura especializada (Andrefsky, 1998, 2005; Brézillon, 1968; Inizan \& alii, 1999; Tixier \& Inizan, 1980), assim como outros trabalhos de análise de líticos para vários contextos da pré-história em Portugal (Bicho, 1993; Zilhão, 1997).

Todos os dados foram recolhidos com acesso ao software E4 (http://www.oldstoneage.com/software/default.shtml.) que permite a criação de uma base de dados automatizada, de forma a permitir resultados homogéneos. A análise destes dados foi feita com recurso ao software $\mathrm{R}$ (https://rstudio. com) e Rstudio (https://rmarkdown.rstudio.com), que permite a criação de scripts totalmente reproduzíveis, tendo em vista o desenvolvimento de uma ciência transparente e opensource.

\section{RESULTADOS}

A amostra é composta por 2170 artefactos líticos (excluindo esquírolas e fragmentos não identificáveis) (Tabela 2). As camadas com maior quantidade de materiais líticos são a camada PITi e camada 2 $(n=650$ e $n=511$, respetivamente), ambas com frequências superiores a $20 \%$ relativamente ao total da coleção. Seguem-se as camadas 3, 4 e 9, com um decréscimo de artefactos significativo. De uma forma geral, parece haver uma diminuição do número de artefactos líticos ao longo da estratigrafia, com uma maior frequência nas camadas superiores.

Em todas as camadas, são as lascas a classe de artefactos líticos mais presente, com frequências superiores a $35 \%$, seguidas dos produtos alongados (suportes com comprimento igual ou superior a duas vezes a largura), núcleos e utensílios retocados. A presença de produtos de preparação e manutenção de núcleos está limitada apenas às camadas 2, 3, 4, PIT1, 9 e 12, com números absolutos relativamente diminutos $(<2)$.

No total, as duas áreas apresentam 119 núcleos, sendo que em todas as camadas, esta classe apresenta valores inferiores a $10 \%$, sendo a camada 4 a que apresenta a frequência mais elevada (9.42\%).

As matérias-primas mais presentes no sítio arqueológico são o sílex (caracterizado por uma grande heterogeneidade, raramente aparecendo na forma de seixo; Pereira \& alii, 2015), quartzo e quartzito, ambos frequentemente na forma de seixos, e que podem ser encontrados com facilidade na área envolvente ao sítio arqueológico (Paixão, 2014). As percentagens destas matérias-primas ao longo da estratigrafia apresentam padrões diferentes, variando entre camadas com uma preferência marcada por um tipo de matéria-prima e camadas que apresentam percentagens semelhantes para todos os tipos de matérias-primas (Figura 4). Nas camadas 6, X e $\mathrm{Z}$, as camadas mais antigas identificadas na área $\mathrm{S} 1 \mathrm{e}$ constituindo os níveis de transição entre o concheiro e as areias base, o quartzito apresenta percentagens superiores a $50 \%$, atingindo quase os $80 \%$ na camada X. Demarca-se ainda a alta frequência de quartzo na camada PIT1 (44\%) comparativamente às outras matérias-primas. De forma semelhante, as camadas 10 e 12 apresentam frequências de artefactos em sílex mais altas que as outras camadas.

No total foram identificados 16 tipos de utensílios retocados, com uma alta frequência de geométri$\cos (\mathrm{n}=115)$, comparativamente às outras tipologias (Tabela 3). Os geométricos mais presentes são os triângulos, como de resto havia já sido atestado em estudos anteriores sobre o Cabeço da Amoreira (Paixão \& alii, 2018). As camadas com maior presença de geométricos são a camada $2(\mathrm{n}=39), 4$ $(\mathrm{n}=18), \operatorname{PIT1}(\mathrm{n}=25)$ e 9 (20), que correspondem com as camadas com maior quantidade de artefactos líticos. A única exceção é a camada 3, com considerável número de materiais, mas na qual foram apenas identificados 7 geométricos. 
As outras tipologias de retocados apresentam números mais reduzidos. As tipologias mais presentes são as lascas retocadas $(n=11)$ e entalhes $(n=10)$, ainda com a presença de truncaturas $(n=5)$, lamelas retocadas $(n=5)$, denticulados $(n=4)$, peças esquiroladas $(\mathrm{n}=3)$ e lamelas de dorso. Apesar da camada 2 apresentar uma grande quantidade dos utensílios retocados supramencionados, não parece existir um padrão tipológico evidente entre camadas ou áreas. De forma a entender melhor os padrões presentes nas várias camadas do sítio arqueológico, foi utilizada uma abordagem multivariada para explorar a interação entre as variáveis escolhidas. Sendo que estas variáveis eram categóricas, foi utilizada uma Análise de Correspondência Múltipla utilizando as seguintes variáveis: classe, matéria-prima, percentagem de córtex e camada (como variável suplementar). De forma a reduzir a grande variabilidade dentro das variáveis, todas os atributos com uma representação inferior a $5 \%$ foram colapsados numa categoria geral chamada "Outros" antes de correr a análise, e seguindo o exemplo de outros estudos onde uma metodologia semelhante foi aplicada (Cascalheira, 2019).

As duas dimensões apresentadas na Figura 5 explicam $41.1 \%$ da variabilidade da amostra. Na Dimensão 1 (23.7\%) encontra-se uma associação forte entre sílex e utensílios retocados, assim como com produtos alongados, ainda que com uma contribuição mais fraca. Parece ainda haver uma associação entre sílex e a ausência de córtex nos artefactos. Na dimensão positiva da Dimensão 1 encontra-se a associação entre quartzo e quartzito, lascas e núcleos, assim como percentagens variáveis de presença de córtex.

A dimensão 2, que explica 17.4\% da variabilidade da amostra, parece demonstrar a associação de quartzito e outras matérias primas com lascas e presença de $100 \%$ de córtex na face dorsal, em oposição ao quartzo, onde parece ocorrer a maior presença de núcleos. Apesar da maioria das camadas aparecer maioritariamente associada ao centro das duas dimensões, é possível observar alguns padrões mais evidentes, sendo estes, por exemplo, a presença de grandes quantidades de quartzito nas camadas $6, \mathrm{X}$ e Z, já acima mencionado.

No que diz respeito às variáveis métricas, de forma a entender possíveis estratégias de produção diferentes, não só entre os diferentes níveis, mas também entre matérias-primas, foi calculado um índice de alongamento (Comprimento/Largura) para lascas e produtos alongados. As diferenças entre o alongamento e a sua distribuição por matéria prima (quartzo, quartzito e sílex) e camada foram comparadas através de um teste ANOVA. Os resultados demonstram que existe uma diferença significativa real entre as matérias-primas ( $p$-value $=0.00)$, e também significativa entre as diferentes camadas (p-value $=0.01)$, relativamente ao alongamento das lascas e produtos alongados. Através de um teste Tukey, para comparações múltiplas, foi possível confirmar que existem diferenças significativas entre todas as matérias-primas (Tabela 4). A criação de boxplots permitiu então entender que, como expectável, o quartzito apresenta índices de alongamento mais baixos, sendo que o sílex apresenta os índices mais altos (Figura 6).

\section{DISCUSSÃO E CONCLUSÕES}

Apesar de preliminar, a análise dos materiais líticos do sítio arqueológico do Cabeço da Amoreira revela alguns padrões de ocupação interessantes ao longo das camadas. Numa primeira análise, é possível entender a diminuição gradual dos materiais ao longo da estratigrafia, com as camadas mais recentes (2, 3, 4 e PITI) tendo a maior quantidade de materiais, comparativamente com as camadas da base da estratigrafia. Este padrão é semelhante em ambas as áreas, S1 (camadas 2, 3 e 4) e S2 (camadas 2, 3 e PIT1). Esta mudança, que parece ser geral a toda a área escavada do concheiro, pode refletir uma alteração na intensidade da ocupação do sítio ou a mudança na sua funcionalidade, algo sugerido anteriormente tendo em conta as várias datações de radiocarbono existentes para o sítio, tipos de estruturas e enterramentos (Bicho \& alii, 2013). No entanto, esta conclusão carece de alguns dados que permitam entender de forma mais detalhada a estratigrafia de ambas as áreas. Por serem áreas escavadas separadamente, atualmente é desconhecida a relação topográfica entre as camadas de ambas as áreas, incluindo a relação temporal entre, por exemplo, a camada 4 e camada 9 (que em ambas as áreas se encontram abaixo da camada 3). De forma semelhante, o caráter espacialmente limitado da camada PITr permite entender que esta é uma deposição anterior à camada 3 , mas cuja relação cronológica com a camada 9 ou 4 é difícil de estabelecer.

Não obstante, a mudança reportada na quantidade de materiais ao longo da estratigrafia parece ser 
igualmente acompanhada por diferenças na matéria-prima. As três matérias primas aparecem de forma relativamente uniforme na maioria das camadas, ainda que com diferenças funcionais. No entanto, como foi referido, parece existir uma predominância na presença de quartzito nas camadas mais antigas da área Si (camadas 6, X e Z), que correspondem também aos níveis de transição para a base do concheiro. Assim, nesta área, não existe apenas uma diminuição da quantidade materiais, como também uma alteração visível na preferência de matéria-prima utilizada. Esta alteração de preferência parece, mais uma vez, alinhar com a interpretação de que existiram funcionalidades diferentes para o sítio ao longo da sua ocupação.

Foi possível identificar o sílex como utilizado primariamente para a produção de utensílios retocados (na sua maioria geométricos) e produtos alongados. A presença de pouco córtex na maioria dos artefactos em sílex parece revelar uma estratégia de obtenção mais complexa, com a sua obtenção e descorticamento acontecendo possivelmente no lugar de recolha da matéria prima. A presença de índices de alongamento mais altos, quando comparativamente com as outras matérias primas, permitem entender uma produção orientada para a obtenção de produtos finais específicos (lamelas e lâminas), ainda que continue a existir uma componente de lascas bastante relevante.

O quartzo e o quartzito apresentam padrões que parecem refletir estratégias de redução mais expeditas, através da recolha de seixos locais e o seu talhe, que resulta na existência de grandes quantidades de córtex nas peças, assim como a grande quantidade de lascas. Ainda assim, o quartzito é, ao longo da estratigrafia, a matéria prima utilizada de forma mais expedita, sendo que o quartzo apresenta algumas semelhanças ao sílex na produção de produtos alongados. Um padrão interessante também visível na amostra analisada é a existência de uma separação de camadas que oscilam entre a entre a presença marcada de utensílios retocados e a presença de núcleos. Este padrão pode refletir a existência de padrões de descarte diferentes, possivelmente resultado de uma separação intra-sítio entre atividades de talhe e outras atividades, ou ocupações diacronicamente e funcionalmente distintas. No entanto, a resolução temporal atualmente disponível para as várias camadas do sítio, com base nas datações de radiocarbono, não permite ainda entender de forma detalhada estes padrões.
Os padrões acima identificados e as particularidades que apresentam apontam para uma complexidade na utilização do espaço do concheiro que poderá, no futuro, ser explorada de forma mais detalhada, utilizando dados espaciais e abordagens multidisciplinares.

\section{AGRADECIMENTOS}

O trabalho em Muge não seria possível sem o financiamento da Fundação para a Ciência e Tecnologia com o financiamento de três projetos PTDC/HAH/ 64185/2006 e PTDC/HIS-ARQ/112156/2009 e, em curso, o projeto MugePortal - Concheiros de Muge: Um novo portal para os últimos caçadores-recolectores do vale do Tejo, Portugal (PTDC/HAR-ARQ/29680/2017). O apoio da Casa Cadaval tem sido também essencial não só no desenvolvimento dos projetos de investigação, mas também na proteção dos concheiros, assim como o da Câmara Municipal de Salvaterra de Magos que tem apoiado a equipa de investigação em várias dimensões de logística.

João Cascalheira e Célia Gonçalves são financiados pela Fundação para a Ciência e Tecnologia (FCT, contrato DL 57/2016/CP1361/CToo26 e DL 57/2016/ $\mathrm{CP}_{1361 / C T o o 29}$, respetivamente).

\section{BIBLIOGRAFIA}

ALDEIAS, Vera e BICHO, Nuno (2015) - Embedded Behavior: Human Activities and the Construction of the Mesolithic Shellmound of Cabeço da Amoreira, Muge, Portugal. Geoarchaeology: An International Journal oo, pp. 1-20.

ANDREFSKY, William Jr (1998) - Lithics: Macroscopic Approaches to Analysis. Cambridge University Press.

ANDREFSKY, William Jr (2005) - Lithic studies. In Handbook of Archaeological Methods. Rowman Altamira.

BICHO, Nuno (1993) - Technological change in the final Upper Paleolithic of Rio Maior, Portuguese Estremadura. Tese de Doutoramento na Southern Methodist University, Dallas, Texas, EUA.

BICHO, Nuno; CASCALHEIRA, João; MARREIROS, João; PEREIRA, Telmo (2011) - The 2008-2010 excavations of Cabeço da Amoreira, Muge, Portugal. Mesolithic Miscellany, 21, pp. 3-13.

BICHO, Nuno; CASCALHEIRA, João; MARREIROS, João; GONÇALVES, Célia; PEREIRA, Telmo; DIAS, Rita (2013) - Chronology of the Mesolithic occupation of the Muge valley, central Portugal: The case of Cabeço da Amoreira. Quaternary International, 308-309, pp. 130-139. 
BRÉZILLON, Michel (1968) - La dénomination des objets de pierre taillée, Supplément à Gallia préhistoire. Editions du Centre National de la Recherche Scientifique.

CASCALHEIRA, João e GONÇALVES, Célia (2012) - Spatial analysis and site formation processes of the mesolithic shellmiddens of Cabeço da Amoreira (Muge, Portugal). JIA 2011, 1, pp. 75-82.

CUNHA, Eugénia; CARDOSO, João; UMBELINO, Cláudia (2003) - New data on Muge Shell-middens: A contribution to more accurate numbers and dates. Estudos Arqueológicos, 1, pp. 185-198.

DETRY, Cleia e CARDOSO, João (2010) - On some remains of dog (Canis familiaris) from the Mesolithic shellmiddens of Muge, Portugal. Journal of Archaeological Science, 37, pp. 2762-2774.

CORRÊA, Mendes (1933) - Les nouvelles fouilles à Muge (Portugal). In XVe Congrès International d'Anthropologie et d’Archáeologie Préhistorique, Paris. Paris: Librairie E. Nourry, pp.1-16.

INIZAN, Marie-Louise; REDURON-BALLINGER, Michèle; ROCHE, Hélène; TIXIER, Jacques (1999) - Technology and terminology of knapped stone. Nanterre: Cercle de recherches et d'études préhistoriques.

PAIXÃO, Eduardo (2014) - A tecnologia lítica no Mesolítico da Estremadura: o caso da camada 2 do Cabeço da Amoreira. Dissertação de Mestrado na Universidade do Algarve.

PAIXÃO, Eduardo; MARREIROS, João; PEREIRA, Telmo; BICHO, N (2018) - Lithic variability in the Mesolithic shellmiddens of Western Iberian Atlantic Coast: technology, use-wear analysis and raw material sourcing from the Layer 2 lithic assemblage of Cabeço da Amoreira (Muge, Portugal). Journal of Anthropological Archaeology, pp. 1-21.

PEREIRA, Telmo; BICHO, Nuno; CASCALHEIRA, João; MARREIROS, João; PAIXÃO, Eduardo (2015) - Raw material procurement in Cabeço da Amoreira. In BICHO, Nuno; PRICE, T. Douglas; Cunha, Eugénia, eds - Muge 150 $0^{\text {th }}$ : The $150^{\text {th }}$ Anniversary of the Discovery of Mesolithic Shellmiddens: Volume 1. Cambridge: Cambridge Scholars Publishing, pp. 147-16o.

RIBEIRO, Carlos (1884) - Les kioekkenmoedings de la Vallée du Tage, rendu de la IX ${ }^{\mathrm{ème}}$ Session du Congrès International d'Anthropologie e d'Archéologie Préhistoriques. Typographie de l'Académie de Sciences, pp. 279-29o.

ROCHE, Jean (1964/1965) - Note sur la stratigraphie de l'amas coquillier mésolithique de Cabeço da Amoreira (Muge). Comunicações dos Serviços Geológicos de Portugal, XLVIII, pp. 191-199.

ROCHE, Jean (1966) - Balance de un siglo de excavaciones en los concheros mesolíticos de Muge. Empúries: revista de món clàssic $i$ antiguitat tardana, pp. 13-48.
ROLÃO, José (1999) - Del Wurm final al Holocénico en el Bajo Valle del Tajo: (Complejo Arqueológico Mesolítico de Muge). Universidad de Salamanca.

ROLÃO, José; JOAQUINITO, Ana; GONZAGA, M. (2006) - O complexo mesolítico de Muge: novos resultados sobre a ocupação do Cabeço da Amoreira. In BICHO, Nuno; VERÍSSIMO, Hugo, eds - Do Epipaleolítico ao Calcolítico na Península Ibérica: Actas do IV Congresso de Arqueologia Peninsular. Faro: Universidade do Algarve, pp. 27-42.

TIXIER, Jacques; INIZAN, Marie-Louise (1980) - Préhistoire de la pierre taillée. 1. Terminologie et technologie. Valbone: Centre de Recherches et d’Études Préhistoriques.

UMBELINO, Claúdia (2006) - Outros sabores do passado. As análises de oligoelementos e de isótopos estáveis na reconstrucão da dieta das comunidades humanas do Mesolítico Final e do Neolítico/Calcolítico do território português. Tese de doutoramento na Universidade de Coimbra.

VAN DER SCHRIEK, Tim; PASSMORE, David; STEVENSON, Anthony; ROLÃO, José (2007) - The palaeogeography of Mesolithic settlement-subsistence and shell midden formation in the Muge valley, Lower Tagus Basin, Portugal. Holocene, 17, pp. 369-385.

VAN DER SCHRIEK, Tim; PASSMORE, David; MUGICA, Franco; STEVENSON, Anthony; BOOMER, Ian; ROLÃO, José (2008) - Holocene palaeoecology and floodplain evolution of the Muge tributary, Lower Tagus Basin, Portugal. Quaternary International, 189, pp. 135-151.

ZILHÃO, João (1997) - O Paleolítico Superior da Estremadura portuguesa. Lisboa: Edições Colibri. 


\begin{tabular}{|c|c|c|c|}
\hline Camada & Descriçãao & Área SI & Área S2 \\
\hline 2 & $\begin{array}{l}\text { Presença abundante de fragmentos de concha, geralmente Cerastoderma edule, } \\
\text { com grande quantidade de artefactos líticos, conchas perfuradas de adornos } \\
\text { corporais, ossos e fragmentos de pinças de crustáceo. No interior da camada } 2 \\
\text { foram identificadas em determinadas áreas maiores concentrações de conchas, } \\
\text { frequentemente inteiras e praticamente sem sedimento, às quais foram atribuídas } \\
\text { a designação 2b, 2d, 2e e 2r, que correspondem a variações lenticulares laterais na } \\
\text { estratigrafia. Na base desta camada foi ainda exumado um esqueleto, designado } \\
\text { por Enterramento } 3 \text {. }\end{array}$ & $\mathrm{X}$ & $\mathrm{X}$ \\
\hline 3 & $\begin{array}{l}\text { Grande concentração de conhas, com diminuição no número de termoclastos em } \\
\text { relação às camadas anteriores, o desaparecimento total dos elementos cerâmicos, } \\
\text { manutenção da indústria lítica e restos faunísticos em abundância. Foram } \\
\text { identificadas variações na concentração de conchas dentro desta camada às quais } \\
\text { foram atribuídas as designações } 3 \text { a e } 3 \text { b. }\end{array}$ & $\mathrm{X}$ & $\mathrm{X}$ \\
\hline 4 & $\begin{array}{l}\text { Abundantes fragmentos de conchas (Cerastoderma edule) e artefactos líticos, } \\
\text { conchas perfuradas de adornos corporais, ossos (mamíferos, peixes, aves e } \\
\text { pequenos répteis) e fragmentos de pinças de crustáceos. Dentro desta camada } \\
\text { foi individualizada uma concentração de conchas designada 4a e uma estrutura } \\
\text { designada Feature A (Gonçalves \& alii 2018). }\end{array}$ & $\mathrm{X}$ & \\
\hline 6 & $\begin{array}{l}\text { Corresponde ainda a um nível de concheiro, constituída por bolsas arenosas e de } \\
\text { barro, com elevada densidade de seixos com dimensões inferiores a } 2 \mathrm{~cm} \text { e pequenos } \\
\text { fragmentos de fauna malacológica. Foi também identificada uma variação na } \\
\text { camada designada por } 6 \text { b. }\end{array}$ & $\mathrm{X}$ & \\
\hline $\mathrm{X}$ & $\begin{array}{l}\text { Corresponde à interface entre os níveis de concheiro e as areias base (camada Z). } \\
\text { Nesta camada foram identificadas uma estrutura (Feature 2), e um enterramento } \\
\text { (Enterramento } 4 \text { ). }\end{array}$ & $\mathrm{X}$ & \\
\hline Z & $\begin{array}{l}\text { Apresenta uma topografia irregular. A sua escavação permitiu a identificação de } \\
\text { duas estruturas negativas designadas Pit3 e Pit4, localizadas na área norte dos } \\
\text { quadrados K1 e J1. }\end{array}$ & $\mathrm{X}$ & \\
\hline Pitı & $\begin{array}{l}\text { Presença dominante de termoclastos e seixos, fauna e artefactos líticos. Existência } \\
\text { de uma divisão acentuada, em termos de composição sedimentológica e de } \\
\text { materiais arqueológicos, entre esta camada e as restantes. Foram identificadas } \\
\text { várias bolsas de concentração de conchas, designadas por PITıa, PITıb, PITıc } \\
\text { e PITıd. }\end{array}$ & & $\mathrm{X}$ \\
\hline 9 & $\begin{array}{l}\text { Elevada presença de concreções e termoclastos e diminuição do material } \\
\text { arqueológico associado. Dentro desta camada foi também identificada uma } \\
\text { concentração de fauna mamalógica de grande porte e relativamente bem } \\
\text { preservada. A boa delimitação espacial desta concentração levou á sua escavação } \\
\text { como estrutura, a qual foi nomeada Feature B. }\end{array}$ & & $\mathrm{X}$ \\
\hline 10 & Apresenta uma diminuição do número de seixos e termoclastos. & & $\mathrm{X}$ \\
\hline 11 & $\begin{array}{l}\text { Constituída quase na sua totalidade por Scrobicularia plana pouco fragmentadas } \\
\text { e carvões de grandes dimensões, com raros termoclastos e seixos. }\end{array}$ & & $\mathrm{X}$ \\
\hline 12 & $\begin{array}{l}\text { Constituída principalmente por fragmentos de conchas, apresentando também } \\
\text { algumas raízes concrecionadas. }\end{array}$ & & $\mathrm{X}$ \\
\hline
\end{tabular}

Tabela 1-Camadas de proveniência dos materiais utilizados no presente estudo e sua distribuição pelas duas áreas de escavação. 


\begin{tabular}{|c|c|c|c|c|c|c|c|c|c|c|c|c|c|c|c|c|c|c|c|c|c|c|c|c|}
\hline \multirow[b]{2}{*}{ Classe } & \multicolumn{2}{|r|}{2} & \multicolumn{2}{|c|}{3} & \multicolumn{2}{|r|}{4} & \multicolumn{2}{|r|}{6} & \multicolumn{2}{|r|}{$\mathrm{X}$} & \multicolumn{2}{|c|}{$\mathrm{Z}$} & \multicolumn{2}{|c|}{ PIT1 } & \multicolumn{2}{|c|}{9} & \multicolumn{2}{|c|}{10} & \multicolumn{2}{|c|}{11} & \multicolumn{2}{|c|}{12} & \multicolumn{2}{|c|}{ Total } \\
\hline & $\mathrm{n}$ & $\%$ & $\mathrm{n}$ & $\%$ & $\mathrm{n}$ & $\%$ & $\mathrm{n}$ & $\%$ & $\mathrm{n}$ & $\%$ & $\mathrm{n}$ & $\%$ & $\mathrm{n}$ & $\%$ & $\mathrm{n}$ & $\%$ & $\mathrm{n}$ & $\%$ & $\mathrm{n}$ & $\%$ & $\mathrm{n}$ & $\%$ & $\mathrm{n}$ & $\%$ \\
\hline Núcleo & 26 & 5.09 & 11 & 4 & 34 & $9 \cdot 42$ & 1 & 3.45 & 1 & 3.33 & 1 & 2 & 36 & $5 \cdot 54$ & 8 & 4.19 & 1 & 3.12 & - & - & - & - & 119 & 5.48 \\
\hline Frag. Núcleo & 4 & 0.78 & 5 & 1.82 & 1 & 0.28 & - & - & - & - & 1 & 2 & 2 & 0.31 & - & - & - & - & - & - & - & - & 13 & 0.6 \\
\hline EMNP & 6 & 1.17 & 3 & 1.09 & 3 & 0.83 & - & - & - & - & - & - & 5 & 0.77 & 3 & 1.57 & - & - & - & - & 1 & 4 & 21 & 0.97 \\
\hline Frag. EMNP & - & - & - & - & - & - & - & - & - & - & - & - & - & - & 2 & 1.05 & - & - & - & - & - & - & 2 & 0.09 \\
\hline $\begin{array}{l}\text { Produto } \\
\text { Alongado }\end{array}$ & 61 & 11.94 & 20 & 7.27 & 39 & 10.8 & 3 & 10.34 & 2 & 6.67 & 3 & 6 & 74 & 11.38 & 15 & 7.85 & 3 & 9.38 & 1 & 7 & 5 & 19 & 226 & 10.41 \\
\hline $\begin{array}{l}\text { Frag. Produto } \\
\text { Alongado }\end{array}$ & 36 & 7.05 & 14 & 5.09 & 22 & 6.09 & - & - & 1 & $3 \cdot 33$ & - & - & 32 & 4.92 & 5 & 2.62 & 3 & 9.38 & - & - & 3 & 12 & 116 & $5 \cdot 35$ \\
\hline Lasca & 194 & 37.96 & 138 & 50.18 & 157 & 43.49 & 18 & 62.07 & 14 & 46.67 & 23 & 46 & 385 & 59.23 & 111 & 58.12 & 20 & 62.5 & 7 & 47 & 14 & 54 & 1081 & 49.82 \\
\hline Frag. Lasca & 127 & 24.85 & 72 & 26.18 & 81 & 22.44 & 6 & 20.69 & 11 & 36.67 & 21 & 42 & 75 & 11.54 & 22 & 11.52 & 3 & 9.38 & 5 & 33 & 2 & 8 & 425 & 19.59 \\
\hline Retocado & 41 & 8.02 & 12 & $4 \cdot 36$ & 16 & 4.43 & 1 & 3.45 & o & ०\% & - & - & 31 & 4.77 & 16 & 8.38 & 2 & 6.25 & 2 & 13 & - & - & 121 & $5 \cdot 58$ \\
\hline $\begin{array}{l}\text { Frag. } \\
\text { Retocado }\end{array}$ & 16 & 3.13 & - & - & 8 & 2.22 & - & - & 1 & 3.33 & 1 & 2 & 10 & 1.54 & 9 & 4.71 & - & - & - & - & 1 & 4 & 46 & 2.12 \\
\hline Total & 511 & - & 275 & - & 361 & - & 29 & - & 30 & - & 50 & - & 650 & - & 191 & - & 32 & - & 15 & - & 26 & - & 2170 & - \\
\hline
\end{tabular}

Tabela 2 - Classes de artefactos líticos por camada.

\begin{tabular}{|c|c|c|c|c|c|c|c|c|c|c|c|c|}
\hline & 2 & 3 & 4 & 6 & $\mathrm{X}$ & $\mathrm{Z}$ & PIT1 & 9 & 10 & 11 & 12 & Total \\
\hline Raspadeira & 1 & - & - & - & - & - & - & - & - & - & - & 1 \\
\hline Raspadeira carenada & - & - & - & - & - & - & 1 & - & - & - & - & 1 \\
\hline Raspadeira carenada atipica & - & - & - & - & - & - & 1 & 1 & - & - & - & 2 \\
\hline Truncatura & 3 & - & 1 & - & - & 1 & - & - & - & - & - & 5 \\
\hline Truncatura obliqua & - & - & - & - & - & - & 1 & - & - & - & - & 1 \\
\hline Entalhe & 4 & 2 & 1 & - & - & - & 2 & 1 & - & - & - & 10 \\
\hline Denticulado & 1 & 1 & - & - & - & - & 2 & - & - & - & - & 4 \\
\hline Peca esquirolada & 1 & - & - & - & - & - & 2 & - & - & - & - & 3 \\
\hline Geometrico & 39 & 7 & 18 & 1 & 1 & - & 25 & 20 & 2 & 1 & 1 & 115 \\
\hline Lamela de dorso & - & 1 & - & - & - & - & 1 & 1 & - & - & - & 3 \\
\hline Lamela de dorso parcial & - & - & - & - & - & - & 2 & - & - & - & - & 2 \\
\hline Lamela com entalhe & - & - & 1 & - & - & - & - & - & - & - & - & 1 \\
\hline Lamina retocada & - & 1 & - & - & - & - & - & - & - & - & - & 1 \\
\hline Lamela retocada & 1 & - & 2 & - & - & - & 1 & 1 & - & - & - & 5 \\
\hline Lasca retocada & 7 & - & - & - & - & - & 2 & 1 & - & 1 & - & 11 \\
\hline Frente núcleo retocada & - & - & 1 & - & - & - & - & - & - & - & - & 1 \\
\hline Total & 57 & 12 & 24 & 1 & 1 & 1 & 40 & 25 & 2 & 2 & 1 & 166 \\
\hline
\end{tabular}

Tabela 3 - Tipo de utensílio lítico por camada (n).

\begin{tabular}{|l|l|l|l|l|}
\hline & diff & lwr & upr & P adj \\
\hline Quartzo- Quartzito & 0.16698 & 0.05025 & 0.2837 & 0.00234 \\
\hline Silex-Quartzito & 0.433 & 0.31105 & 0.55496 & 0.00 \\
\hline Silex-Quartzo & 0.26603 & 0.13848 & 0.39357 & 3.3 E-o6 \\
\hline
\end{tabular}

Tabela 4-Resultados do teste Tukey para comparações múltiplas sobre a distribuição da variável alongamento de suportes por cada matéria-prima. 

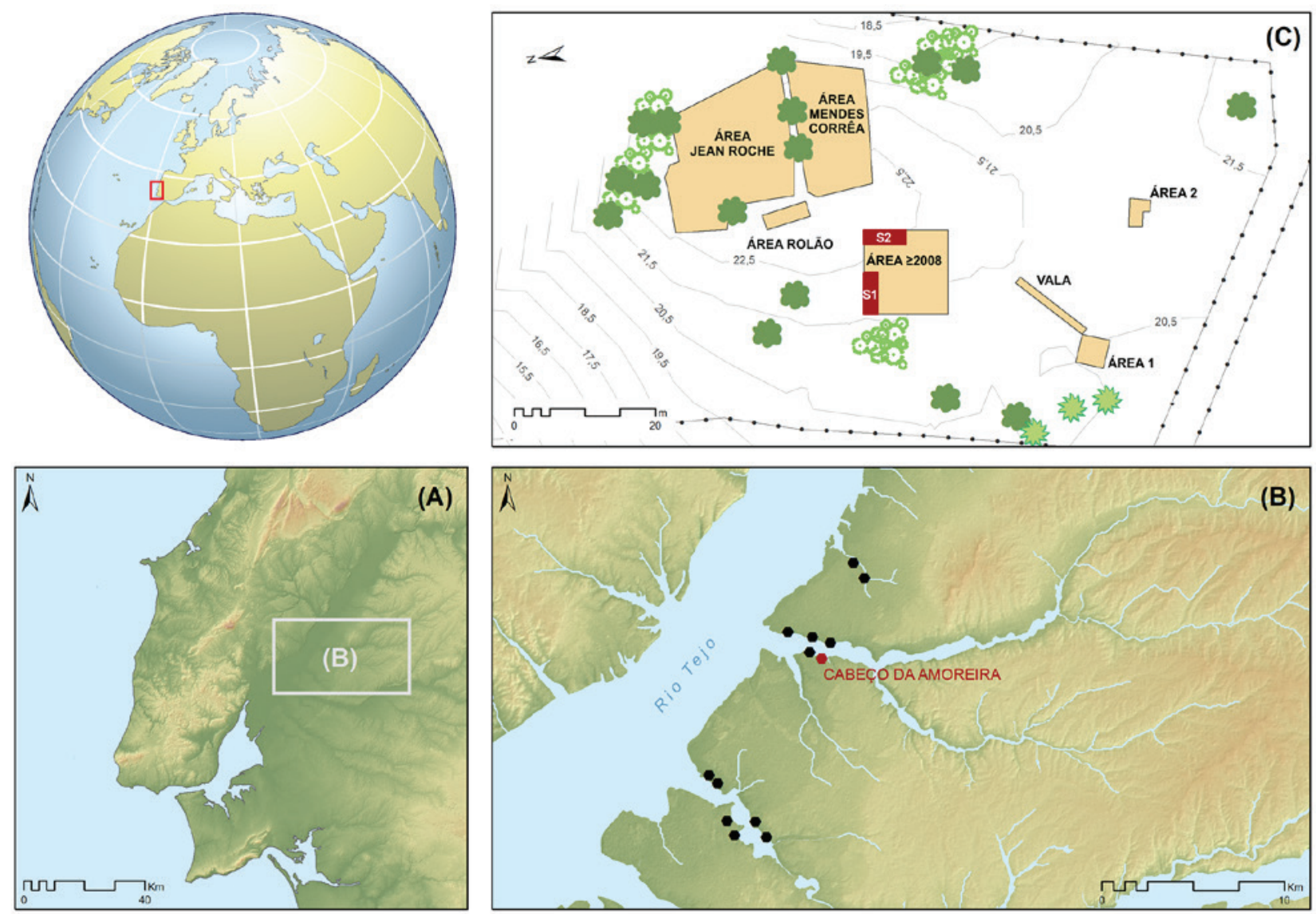

Figura 1-A e B - Localização dos concheiros mesolíticos nas margens das ribeiras Fonte da Moça, Muge e Magos; C-Planta topográfica do sítio arqueológico do Cabeço da Amoreira com a localização das várias áreas intervencionadas. Autor: Célia Gonçalves.

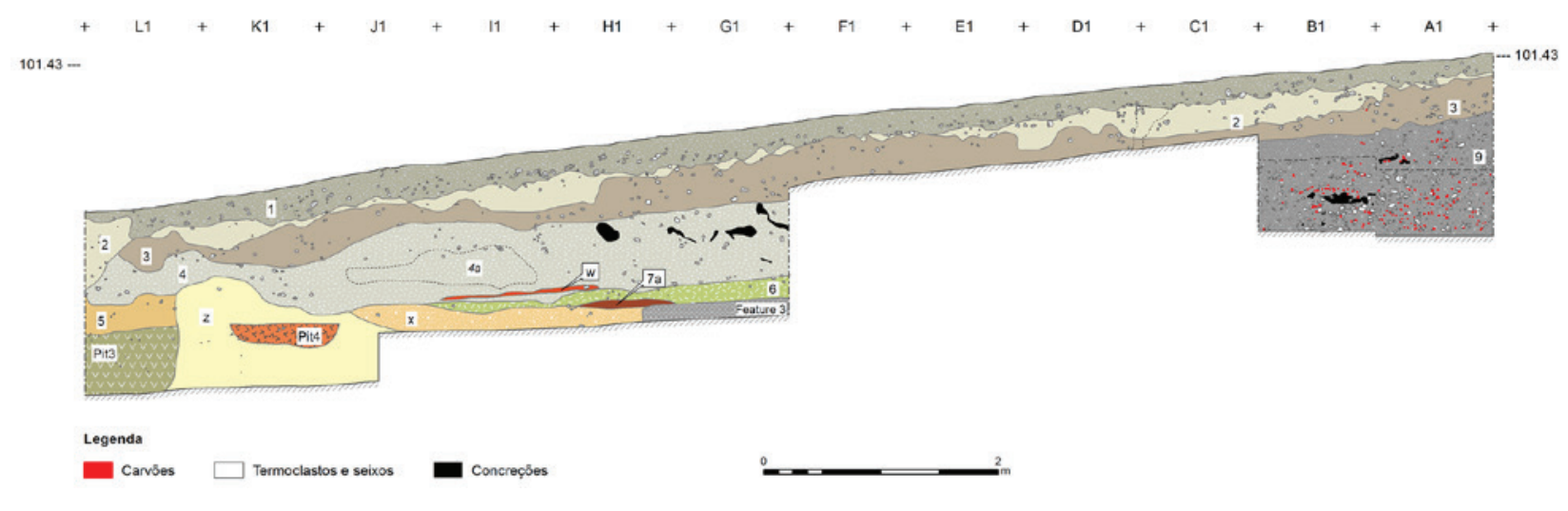

Figura 2 - Desenho do corte norte do concheiro do cabeço da Amoreira. Autor: Célia Gonçalves. 


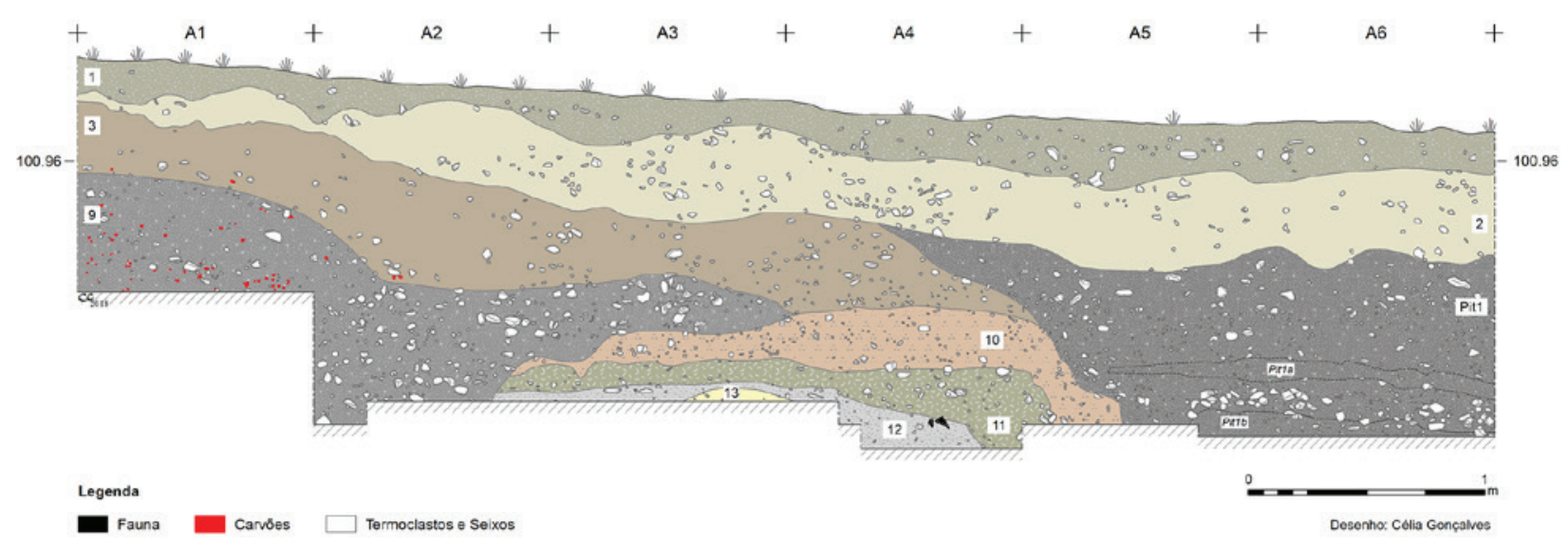

Figura 3 - Desenho do corte este da área S2 do concheiro do cabeço da Amoreira. Autor: Célia Gonçalves.

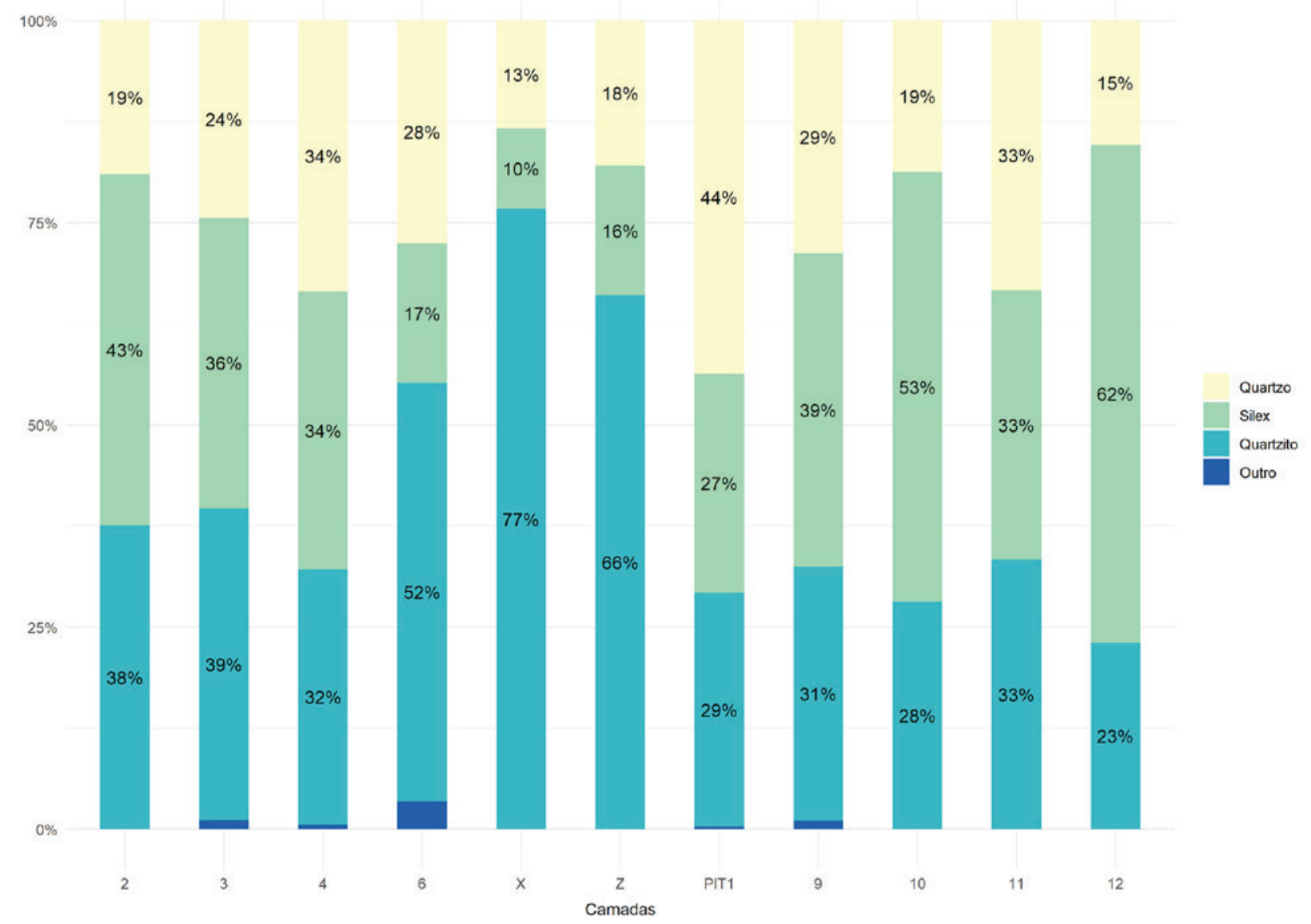

Figura 4 - Percentagem de matérias primas por camada das áreas S1 e S2 do Cabeço da Amoreira. Autor: Joana Belmiro. 


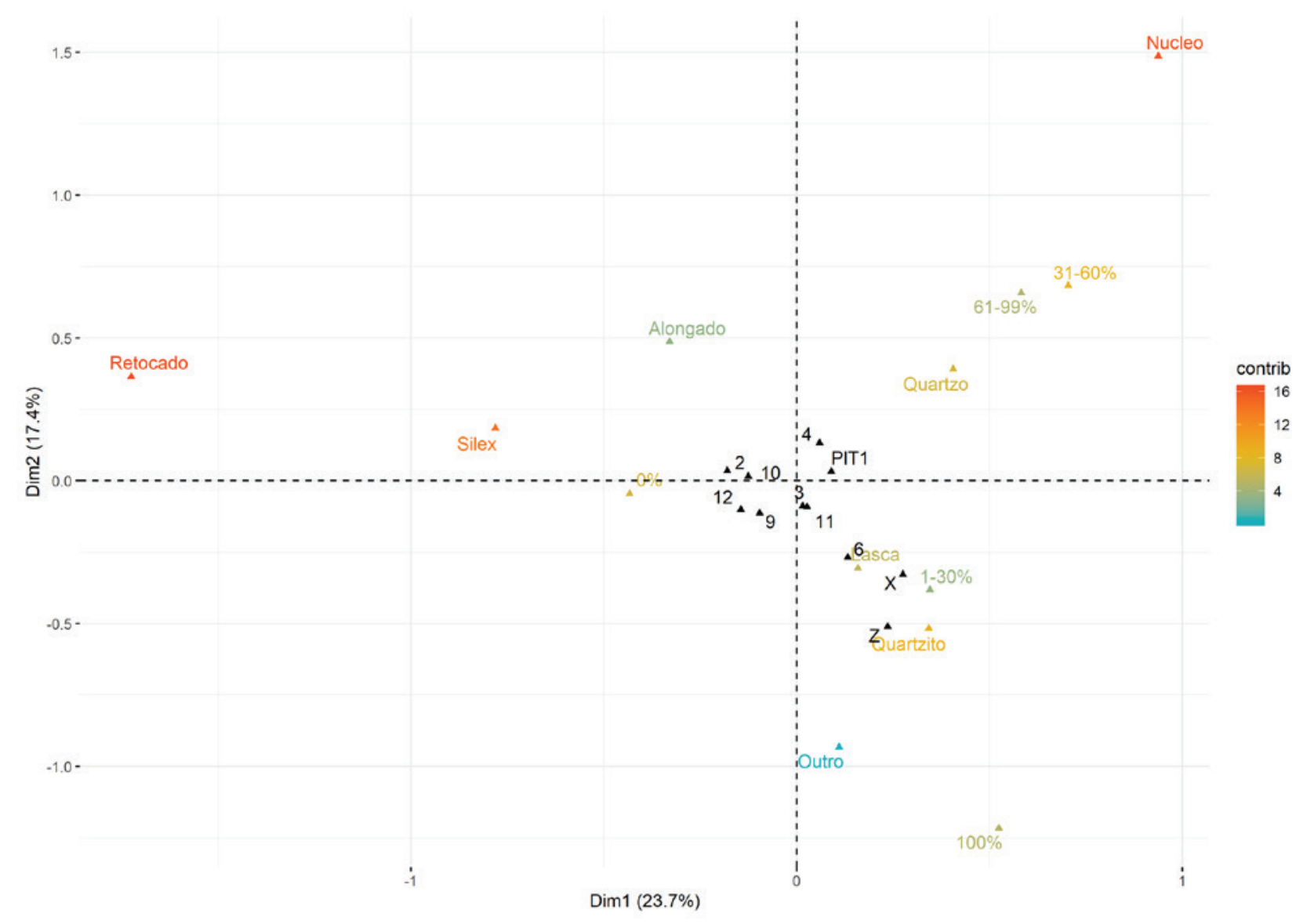

Figura 5-Análise de Correspondência Múltipla para as variáveis matéria-prima, classe de artefacto, percentagem de córtex e camada (variável suplementar). Autor: Joana Belmiro. 


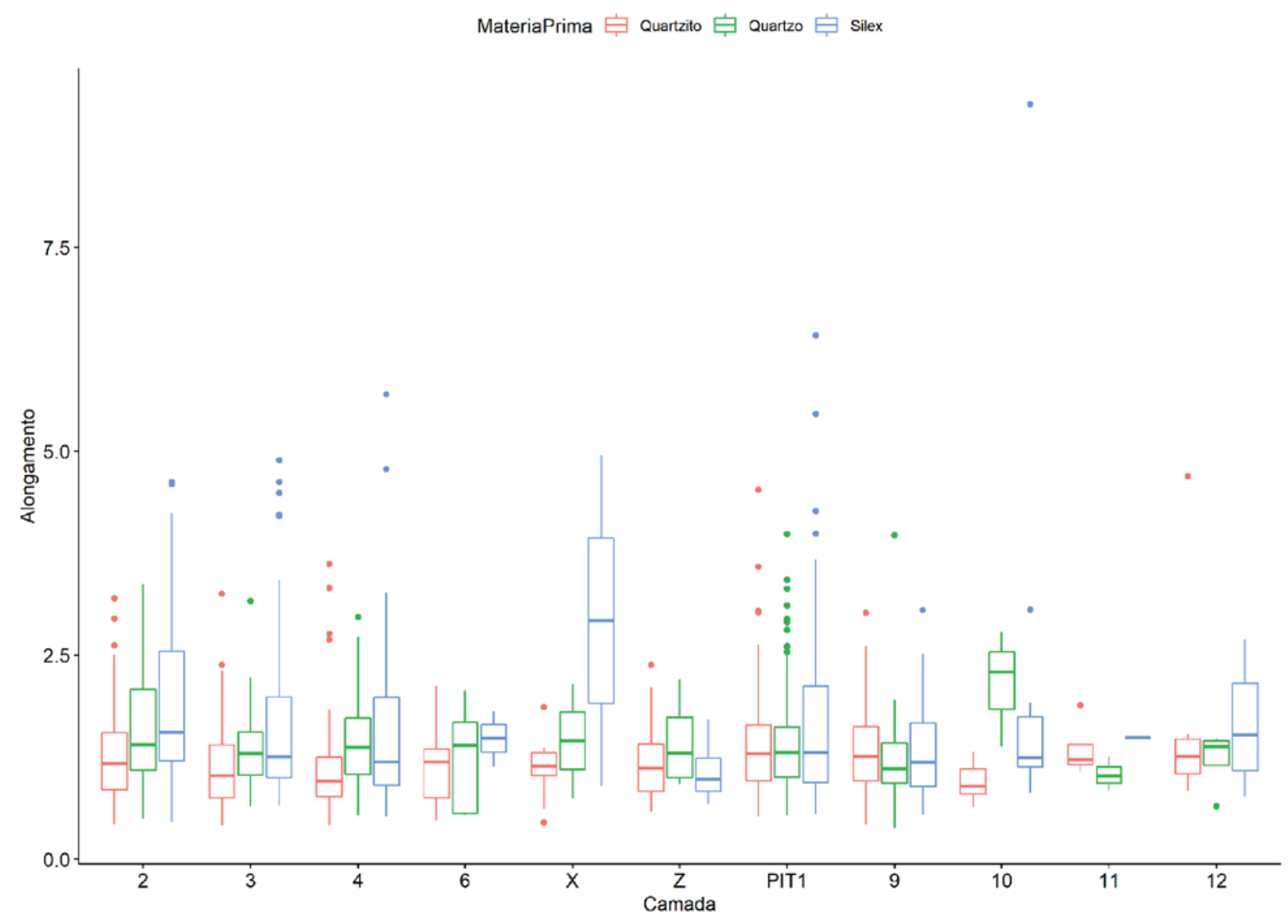

Figura 6 - Boxplot do índice de alongamento de lascas e produtos alongados, por matéria prima e camada. Autor: Joana Belmiro. 



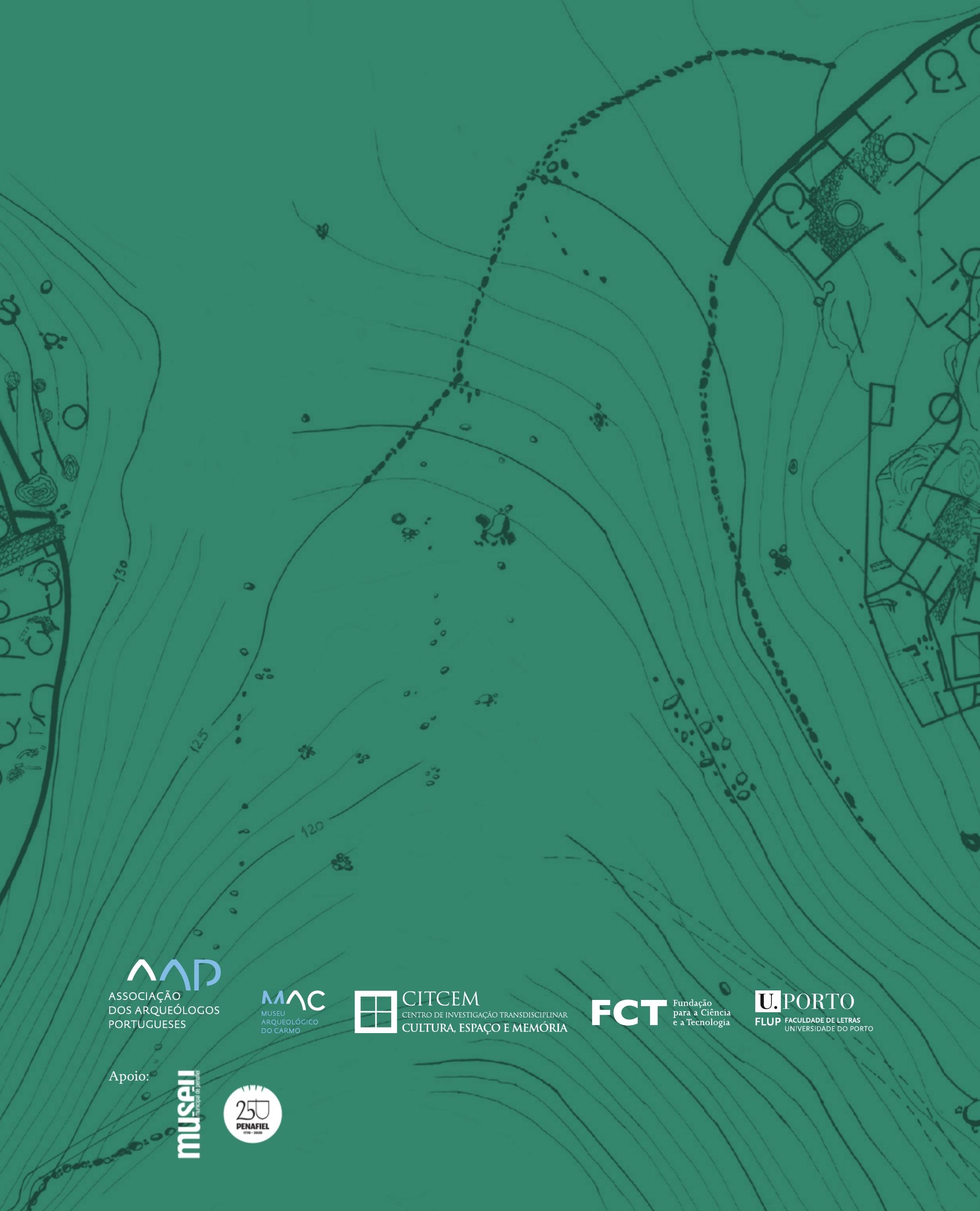

